\title{
A aplicação de abordagens feministas na pesquisa em administração
}

\section{The use of feminist approaches in management studies}

\author{
Isabel Cerchiaro ${ }^{1}$ \\ Eduardo André Teixeira Ayrosa ${ }^{2}$ \\ Deborah Moraes Zouain ${ }^{3}$
}

\begin{abstract}
Resumo
Pretendemos, neste artigo, analisar formas de investigação de questões de administração baseadas na teoria feminista. Tal análise parte indagações da seguinte ordem: se a voz do conhecimento ocidental tem sido constituída diferentemente de "outras" vozes, tornando-as invisíveis, o que aconteceria se essas "outras" vozes pudessem responder? O que aconteceria caso estas vozes pudessem demonstrar como são constituídas como "outras"? O que aconteceria caso essas outras vozes pudessem reclamar suas próprias especificidades, fora dos dualismos (como, por exemplo, masculino/feminino) presentes nos discursos ocidentais do conhecimento (CALÁS e SMIRCICH, 1999, p. 305)? Pensando sobre isso, e sendo este um artigo na área de administração, discorremos sobre as diferentes abordagens feministas e suas metodologias, argumentando que a abordagem feminista multicultural pode ser a mais apropriada para responder algumas questões sobre o modo como as mulheres constroem sua forma de pensar no nosso mundo pós-colonial. Evidenciamos também as posições e relações de sujeitos heterogêneos, diferentes das imagens raciais e de gênero produzidas pelas categorias ocidentais (como 'mulheres', 'negra') (CALÁS; SMIRCICH 1999; FONSECA 1999; TONG 1998).
\end{abstract}

Palavras-chave: feminismo; abordagens feministas; metodologia.

\begin{abstract}
It is our intention to show alternative approaches regarding feminist research. It is based in one of the authors' questionings on how to make an "invisible" person be seen, i.e., express oneself and what this person has to say. What would happen if they could present themselves as "others", as different. How women can express themselves outside the colonial dichotomies of male/female discourses? This paper presents different feminist approaches and their methodologies, and sees the multicultural approach as the one that can better answer how women build their thoughts in a pos-colonial world. It is also our aim to show that knowledge production is a way to legitimize colonialism, since it assumes what the "other" thinks (CALÁS; SMIRCICH, 1999; TONG, 1998), demonstrating also the difference on heterogeneous subjects, different racial images and gender as "occidental" categories (such as 'women' or 'black woman') (CALÁS; SMIRCICH, 1999; FONSECA, 1999; TONG, 1998).
\end{abstract}

Key words: feminism; feminist approaches; methodology.

\footnotetext{
${ }^{1}$ Doutorado em Administração pela Escola Brasileira de Administração Pública e de Empresas da Fundação Getulio Vargas - EBAPE / FGV. Mestrado em graduação em Administração da Escola de Gestão e Negócios da UNIGRANRIO. Endereço: Rua da Lapa, 86 - $9^{\circ}$ andar - Centro - Rio de Janeiro - RJ - Brasil - CEP: 20021-180. E-mail: icerchiaro@uol.com.br.

2 PhD. em Administração pela London Business School. Chefe de Centro da Graduação da Escola Brasileira de Administração Pública e de Empresas da Fundação Getulio Vargas - EBAPE/FGV. Professor da EBAPE/FGV. Endereço: Praia de Botafogo, 190 - sala 528 - Botafogo - Rio de Janeiro/RJ - Brasil CEP: 22250-900. E-mail: Eduardo.ayrosa@fgv.br

3 Doutora em Engenharia de Produção pela Universidade Federal do Rio de Janeiro. Vice-Diretora da Escola Brasileira de Administração Pública e de Empresas - EBAPE/FGV. Endereço: Praia de Botafogo, 190 - sala 521 - Botafogo - Rio de Janeiro/RJ - Brasil - CEP: 22250-900. E-mail. deborah.zouain@fgv.br
}

Artigo submetido em dezembro de 2008 e aceito em março de 2009 


\section{Introdução}

Se a voz do conhecimento ocidental tem sido constituída diferentemente de "outras" vozes, tornando-as invisíveis, o que aconteceria se essas "outras" vozes pudessem responder? O que aconteceria caso estas vozes pudessem demonstrar como são constituídas como "outras"? O que aconteceria caso essas outras vozes pudessem reclamar suas próprias especificidades, fora dos dualismos (como, por exemplo, masculino/feminino) presentes nos discursos ocidentais do conhecimento (CALÁS e SMIRCICH, 1999, p. 305)? Embora, segundo dados do censo do IBGE de 2000, mulheres totalizem cerca de 51\% da população brasileira, isso não parece ser suficiente para que elas atraiam os acadêmicos brasileiros da área de administração. De 1997 até hoje, apenas 48 trabalhos publicados nos eventos da ANPAD tiveram como temática o ponto de vista feminino, dos quais apenas dois na área de marketing (diga-se de passagem, escritos por homens!).

Um aspecto que pode explicar a falta de interesse da academia de administração por esse público tão amplo é o fato de que, em 2000, 77\% dos acadêmicos da área de marketing são homens (VIEIRA, 2000). Um estudo conduzido por Cerchiaro (2003), parece corroborar a mesma conclusão em relação aos autores de artigos da área de marketing dos EnANPADs. De acordo com este estudo, em 2002, mais de 68\% dos autores eram homens. Sendo a academia aparentemente um lugar de homens, que acreditam na neutralidade do conhecimento ali gerado, parece justificado que tal conhecimento seja aplicável a todos os gêneros.

Essa perspectiva vem sendo desafiada por várias acadêmicas (BRISTOR; FISCHER, 1993; CALÁS; SMIRCICH, 1999; CATTERALL et al. 1997, entre outras). O primeiro desafio recai sobre a validade desse conhecimento. Todo conhecimento gerado por homens reflete a perspectiva masculina (CATTERALL et al. 1997) e, portanto, é passível de revisão por outro tipo de olhar.

Um segundo desafio à centralidade masculina na produção científica em administração recai sobre a origem do conhecimento, no sentido da geração de novos conhecimentos. Não só o conhecimento é produzido com a predominância de autores estrangeiros, mas a maioria destes autores são do Gênero masculino. O estudo de Hemais e Vergara (2001) sobre citações na área de estudos organizacionais revelou que $70 \%$ dos autores citados na Revista de Administração de Empresas, na Revista de Administração Pública, na Revista de Administração da Universidade de São Paulo e nos anais dos encontros anuais da ANPADs eram estrangeiros. No mesmo estudo, entrevistas com os autores revelaram que a predominância de autores estrangeiros nas citações "deve-se à maior variedade de fontes estrangeiras e à inércia dos pesquisadores brasileiros" (Ibidem, p.46). No estudo conduzido por Cerchiaro (2003), foi observado que, entre os trabalhos apresentados na divisão de marketing no EnANPAD de 2002, autores estrangeiros representaram mais de $88 \%$ das referências, incluindo-se aí livros, dissertações e, principalmente, artigos. Isso indica a dependência dos autores brasileiros das idéias que vêm de fora. Vieira (1998) já havia identificado essa dependência, comparando o número de citações de periódicos internacionais com o de periódicos brasileiros. Isso, de certa forma justifica o comentário de Douglas e Craig (1992) de que a América Latina é negligenciada em estudos de marketing, já que o conhecimento gerado aqui, acaba por não atrair a atenção do resto do mundo, visto serem meras replicações.

Este artigo propõe, portanto, a aplicação de abordagens feministas que sejam apropriadas para captar, descrever e interpretar a realidade brasileira. $\mathrm{O}$ artigo discorrerá sobre as várias abordagens existentes, e argumentar por quê a abordagem multicultural parece ser a mais adequada para a tarefa em questão. Tal abordagem propõe que a produção do conhecimento no ocidente (centro) é uma forma de autopromoção, implicando a legitimação do imperialismo e do colonialismo (MINH-HA, 1989; PRAKASH, 1995; SAID, 1978; 1989), e que a função das acadêmicas é a desconstrução dos textos ocidentais. Essa abordagem freqüentemente focaliza as complexas subjetividades produzidas pelas interseções de gênero, raça, classe, etnia etc. no contexto de relacionamentos 
específicos entre Primeiro e Terceiro mundos. Teoriza, portanto, sobre posições e relações de sujeitos heterogêneos, diferentes das imagens raciais e de gênero produzidas pelas categorias ocidentais (como "mulheres", "negra") (CALÁS; SMIRCICH, 1999, p.305).

Ao considerar novamente a abordagem multicultural $\square$ com as complexas subjetividades geradas em suas interseções de gênero, classe e raça e na diferença de contextos entre Primeiro e Terceiro mundos $\square$, acreditamos ser essa abordagem bastante apropriada para representar a realidade brasileira. Devemos levar em consideração nossa posição não só como aculturados, mas também como aculturadores. Afinal, quando nós, acadêmicos, que produzimos conhecimento, somos também o centro, do ponto de vista da periferia, das classes menos favorecidas.

Casals (1998) afirma que nos países latino-americanos, tradicionalmente, importamos as políticas públicas formuladas nos países de Primeiro Mundo e que essas "importações institucionais têm como pressuposto um alinhamento com os novos movimentos políticos mundiais e uma necessidade de inserção entre as ditas nações desenvolvidas" (Ibidem, p.1). Entretanto, afirma também que a implementação de políticas "importadas" tem produzido resultados contrários aos esperados na América Latina. Não devemos esquecer de mencionar os problemas com a implementação de práticas dos países colonizadores sem a devida adaptação para o ambiente onde será implantado, conforme mencionado por Guerreiro Ramos (1996), Pollitt (1993) e Wood e Caldas (2002). Podemos discutir esse ponto de vista também na importação de modelos metodológicos, como bem questionou Guerreiro Ramos (1996): "O fato mais auspicioso que indica a constituição, no Brasil, de uma ciência nacional, é o aparecimento da consciência crítica de nossa realidade." A partir da crítica aos modelos estrangeiros, podemos começar a pensar um modelo brasileiro.

Wood e Caldas (2002) corroboram essa discussão. Discutindo o ambiente empresarial, eles nos dão algumas "pistas" sobre as razões da importação de modelos estrangeiros não terem dado certo no Brasil, embora sejamos fortemente atraídos pelos modelos criados nos países desenvolvidos. Segundos esses autores, dois traços presentes na personalidade do brasileiro levam a sermos mais receptivos à importação de práticas gerenciais: plasticidade (abertura e permeabilidade a influências estrangeiras) e o formalismo (tendência à adoção de comportamento de "fachada", o que resulta em uma discrepância entre o real e o formal). Um exemplo da adoção de programas "importados" sem a devida discussão e adaptação pode ser encontrado nos programas de qualidade total (PQT). Segundo Mendes (2001), um alto grau de implantação de programas de qualidade total "parece contribuir para reduzir o desconhecimento dos usuários dos serviços públicos sobre cidadania" (p.9). O que não fica claro no artigo dessa autora é a relação entre causa e efeito: se um alto grau de implantação de PQT leva a um maior conhecimento sobre cidadania ou se o conhecimento sobre cidadania leva o cidadão a demandar melhor serviço.

Importa, portanto, ressaltar que pesquisas realizadas em outros países, com metodologias supostamente neutras, refletiram o ponto de vista masculino dos pesquisadores. Acadêmicas feministas criticam o conhecimento existente como uma construção masculina, e não neutra, como os acadêmicos (na sua maioria, homens) nos querem levar a crer (CATTERALL et al, 1997). Como veremos mais adiante, na abordagem feminista multicultural, o "conhecimento" é visto como um sistema de relações de poder imposto pelo Ocidente ao "resto" do mundo; portanto, os conhecimentos ou as subjetividades dos outros também são possíveis. Catterall et al (1997) afimam que a teoria e a pesquisa feminista devem incorporar tanto a crítica social quanto as mudanças sociais, o que é por demais importante para estudarmos a realidade brasileira. Desse modo, uma abordagem feminista busca oferecer teorias alternativas que melhor exprimam o olhar feminino. Isso abre espaço para o trabalho proposto: Qual a abordagem feminista mais adequada para explicar a realidade das mulheres brasileiras? 


\section{Objetivos}

Não é difícil observar que a área de qualidade de serviços tem merecido uma atenção maior de pesquisadores. O que não é tão claro é a diferença entre os gêneros na forma de perceber o fenômeno. Um estudo conduzido por Cerchiaro em 1996 demonstrou que-existem diferenças na percepção de qualidade de serviços bancários percebida entre respondentes do gênero feminino e do gênero masculino. Este resultado abriu caminho para o trabalho proposto aqui. Afinal, se existem de fato diferenças detectadas na avaliação de serviços bancários entre homens e mulheres, e se as formas de avaliação de qualidade percebida se serviços são baseadas em teoria "neutra", há espaço para uma melhor compreensão da forma como mulheres avaliam produtos, serviços, ou quaisquer outros conceitos, se instrumentos que emanem de suas próprias formas de vida, e melhor as representem, sejam desenvolvidos. Há espaço, portanto, para reflexão sobre como melhor representar mulheres brasileiras em pesquisas na área de administração em geral, e particularmente de marketing.

Desta forma, o objetivo deste artigo é rever as várias abordagens feministas existentes e explicar por que a abordagem multicultural pode ser a mais adequada para o estudo da realidade feminina brasileira.

\section{Justificativa}

A histórica associação entre objetividade e os homens e entre subjetividade e as mulheres leva a preocupações sobre a suposição de que as mulheres podem ser objetos, mas nunca sujeitos do conhecimento; conhecidas, mas não conhecedoras (CALÁS; SMIRCICH, 1999).

Muitas mulheres entram em conflito em relação as suas disciplinas e as suas experiências pessoais porque acreditam que a prática da pesquisa, da perspectiva masculina, acaba compelindo-as a descartarem ou reprimirem seu mundo de experiências como uma fonte válida de informações (BRISTOL; FISCHER, 1993). Já as experiências masculinas e seus pontos de vista resultantes são fundamentalmente diferentes, pois os homens têm dificuldade de fazer perguntas objetivas ou de desenvolver teorias objetivas sobre assuntos relacionados a experiências dos "outros" (BRISTOR; FISCHER, 1993). Portanto, todo conhecimento é aberto a revisões, visto que só pode ser apreendido através de categorias que formem a percepção.

\section{Relevância do estudo: benefícios para o mundo acadêmico que poderão advir da resposta ao problema}

Segundo Douglas e Craig (1992), a América Latina é negligenciada nos estudos de marketing.

Uma tradição de pesquisa ainda tem que ser estabelecida, e a falta de pesquisadores na área de marketing, tanto dentro quanto originários desses países, aparentemente, resulta num desinteresse por examinar tais mercados. Como esses mercados começam a oferecer maiores oportunidades, faz-se necessário examinar e identificar assuntos que lhes sejam específicos. (DOUGLAS; CRAIG,1992, p.295)

Há uma carência de estudos na área de administração que adotem uma ótica feminista. Embora várias pesquisas tenham sido feitas na área de comportamento do consumidor (ver BRISTOR; FISCHER, 1993; CATTERALL et al, 1997, para uma revisão sobre o assunto), poucos trabalhos foram conduzidos no Brasil (até 2007, apenas 14 tinham sido publicados).

$\mathrm{O}$ artigo aqui apresentado pretende dar uma contribuição singular para o melhor conhecimento da forma de pensar feminina no Brasil. Tal objetivo decorre da constatação de que a área de administração de serviços carece de estudos com uma perspectiva feminista, como verificado na maioria dos trabalhos acadêmicos, especialmente, levando-se em conta abordagens como a radical, a pós-estrutural/pós-moderna e a multicultural. 


\section{Relevância do estudo: benefícios para as organizações que poderão advir deste estudo}

Como este artigo pretende ser uma contribuição singular ao propor uma nova metodologia para o estudo dos problemas do universo feminino, esta sua abordagem poderia ser aplicada a qualquer campo da administração, entre os quais o da administração pública, o que segundo Farah (2004) seria mais pertinente ainda, devido à falta de participação das mulheres na elaboração de políticas públicas do seu interesse.

Segundo a lógica empresarial, os administradores públicos devem identificar quais as necessidades básicas e tentar superar as expectativas nas dimensões que realmente irão fazer diferença para eles. Saber a diferença é primordial para melhorar a percepção do serviço prestado. Os consumidores se encontram na posição de dizer o que querem por ordem de importância. Empresas e governos podem, nesse caso, associar as necessidades dos consumidores com suas próprias competências, maximizando a percepção de qualidade de serviço (EVANS, 1995).

Entretanto, antes disso, cabe discutir e questionar a validade dessa argumentação. Wood e Caldas (2002) chamam a atenção para os problemas que podem advir da implementação "cega" de práticas empresariais exógenas. Dobel (2001), Mintzberg (1996) e Rosenbloom (2001) destacam o quanto é arriscado tomar os cidadãos como meros consumidores, prática defendida pelo new public management. Afinal, não devemos confundir o privado com o público (que deveria se chamar de estatal, já que o Estado é o dono), porque, no primeiro caso, a empresa tem que servir, antes, aos acionistas, enquanto no segundo caso, o Estado age em prol do público (MINTZBERG, 1996).

É importante demonstrar que o trabalho aqui proposto visa oferecer informações importantes para melhor compreender a estrutura das necessidades e anseios do público feminino, tão deixado de lado na elaboração das políticas públicas (FARAH, 2004). Através de um estudo sobre a ótica feminista, pretendemos demonstrar que, se conhecermos melhor o ponto de vista das mulheres, desenvolvendo um pensar que lhes seja próprio, daremos uma importante contribuição para a formulação de políticas públicas e, porque não dizer, para a sociedade como um todo.

\section{Abordagens feministas}

Meu próprio sexo, espero, irá desculpar-me se as trato como crianças racionais, em vez de lisonjearlhes sua graça fascinante, vendo-as como se vivessem uma infância permanente, incapazes de andar com suas próprias pernas. Eu gostaria de indicar em que consistem as verdadeiras dignidade e felicidade humanas $\square$ quero persuadir as mulheres a se esforçarem para adquirir força, tanto da mente quanto do corpo. (MARY WOLLSTONECRAFT, 1792)

Segundo Cudd e Andreasen 2005), a teoria feminista é uma tentativa de dar um sentido e, depois, criticar a subordinação da mulher ao homem. Por sustentar a idéia de crítica social através do desvelamento dessa subordinação e de suas implicações morais e políticas, a teoria feminista possibilita visões de alteridade em relação à sociedade, o que no estudo aqui desenvolvido é mais pertinente ainda devido à falta de participação das mulheres na elaboração de políticas públicas do seu interesse (FARAH, 2004). Ainda quanto a esse aspecto, conforme Jaggar (2004), a principal preocupação da crítica feminista é expor as múltiplas formas pelas quais os homens são privilegiados e opor-se à discriminação das mulheres. Corroborando esse ponto de vista, Zuckerman e Carsky (1992) argumentam que a "escondida" agenda acadêmica sobre homens e mulheres influenciou os temas tratados pela academia e, por extensão, os esquemas teóricos, a formulação das perguntas de pesquisa, as escolhas metodológicas e a coleta de dados, bem como a interpretação dos resultados e as conclusões tiradas. Calás e Smircich (1999) argumentam, seguindo o mesmo raciocínio, que as teorias "feministas" não dizem respeito, apenas, aos temas relativos "às mulheres", pois ao adotarmos essas teorias como lentes conceituais, ampliamos o campo de estudo, passando a considerar as questões dos outros, que são 
diretamente afetados. Assim, teorias feministas articulam problemas que, de outra forma, poderiam continuar sendo ignorados.

Um ponto a ser observado nas abordagens feministas é a diferença entre "sexo" e "gênero". "Sexo" é biologicamente definido, relacionado às diferenças morfológicas entre homens e mulheres (COSTA, 1994). Quanto ao "gênero", é "sociologicamente construído, um produto da socialização e vivência" (CALÁS; SMIRCICH, 1999, p.276). Costa (1994) amplia o conceito de "gênero", de forma a abranger suposições associadas, estereótipos e expectativas sociais. "A psicologia individual e aspectos da personalidade, os papéis sociais envolvendo trabalho, lazer, a casa e outras atividades e interações, as responsabilidades na produção e na reprodução, as expectativas de comportamento e, até mesmo, a forma de se vestir e de falar, tudo se torna 'gênero tipificado' na construção dos papéis dos gêneros". (COSTA, 1994, p.372).

Calás e Smircich (1999) e Tong (1998) classificam a teoria feminista em sete diferentes abordagens (embora Tong proponha uma oitava, o ecofeminismo): liberal, radical, psicanalítica, marxista, socialista, pósestruturalista/pós-moderna, e multicultural (terceiro-mundista ou pós-colonialista). Para este artigo, acreditamos que três seriam particularmente pertinentes: a radical, a pós-estruturalista/pós-moderna, e a multicultural). De qualquer forma, a conclusão buscará demonstrar que a abordagem multicultural é a abordagem mais interessante para abordar não só questões sobre a mulher, mas principalmente, os problemas que envolvem mulheres propostos na área de administração em geral, e de marketing em particular.

\section{Abordagem liberal}

Surgiu com base na teoria política dos séculos XVIII e XIX, calcada na quebra do paradigma predominante sobre a natureza humana. Sua maior preocupação era demonstrar que as mulheres eram tão "humanas" quanto os homens (TONG, 1998). Para os adeptos dessa abordagem, enquanto "sexo" é uma característica natural, o "gênero" é uma categoria socialmente determinada. A idéia de uma "boa sociedade" é a de uma sociedade justa que permite aos indivíduos o exercício da autonomia e a realização pessoal (CALÁS; SMIRCICH, 1999, p.279).

A pesquisa na abordagem liberal segue, de acordo com Burrell e Morgan (1982), epistemologias positivistas compatíveis com o paradigma funcionalista. Essa epistemologia é tida como "neutra" quanto aos aspectos de gênero; geralmente, utilizando metodologias positivistas, experimentos de laboratório e análises eminentemente quantitativas (CALÁS; SMIRCICH, 1999; TONG, 1998).

\section{Abordagem radical}

Surgiu na década de 1960, a partir dos movimentos feministas contemporâneos de luta pelos direitos humanos (TONG, 1998). Nessa abordagem, o tema central dos pesquisadores é a subordinação das mulheres, visto que a preocupação das feministas com as questões a elas relacionadas surgiu do seu desejo por melhores condições de vida. Este foi resultado da participação em movimentos radicais, como o dos direitos civis, e do envolvimento com a esquerda política e com o movimento pacifista contra a Guerra do Vietnã / movimento pacifista (em contraste com a Guerra do Vietnã).

Várias estudiosas partem da "teorização centrada na mulher" com base nas suas vidas e experiências para criar conceitos básicos. Essa abordagem vê os humanos, fundamentalmente, como seres corpóreos sexuados. As mulheres são o primeiro grupo oprimido, e tal opressão provê um modelo conceitual para entender qualquer outra forma de opressão (TONG, 1998). É um modelo radical por centrar-se nas mulheres, o qual, através do entendimento dessa dominação por elas sofrida, visa criar uma nova ordem na qual não sejam subordinadas aos homens (CALÁS; SMIRCICH, 1999).

Para os seguidores dessa abordagem, a concepção de sexo/gênero teoriza sobre a existência de "classes sexuais". Essa divisão por classe é que colocaria as mulheres na condição de uma classe oprimida. Quanto ao 
gênero, é visto como uma construção social que assegura a subordinação das mulheres aos homens. A sexualidade, no caso do heterossexualismo, é caracterizada por ideologias da objetificação (homens são sujeitos - senhores; mulheres são objetos - escravos) (TONG, 1998, p.63). O lesbianismo, por sua vez, é visto como uma forma feminina de controle da sexualidade da mulher. Tong (1998, p.69-70) afirma que não há nenhuma razão psicológica feminista para que uma mulher queira ter sexo com um homem; muito pelo contrário, existem apenas motivos psicológicos não-feministas para uma mulher querer fazer sexo com um homem.

A sua concepção de "boa sociedade" é uma sociedade livre de distinções de gênero ou de sexo (ou talvez um matriarcado, de preferência, livre de homens). A maternidade é vista não apenas como algo biológico, mas também social, exigindo da mulher um enorme esforço, tanto em relação ao corpo quanto às energias (TONG, 1998).

Sua posição epistemológica é a de que o conhecimento holístico centrado no feminino é possível, mas fora das estruturas patriarcais, e que se os homens adotam procedimentos impessoais para chegar à verdade, as mulheres recorrem à interconectividade, na qual a verdade emerge da empatia e da compreensão (ZUCKERMAN; CARSKY, 1992). Para poder trabalhar o conhecimento de forma holística, as metodologias interpretativistas seriam mais recomendadas (ZUCKERMAN; CARSKY, 1992), tais como grupos de conscientização e estudos de casos (CALÁS; SMIRCICH, 1999, p.279).

Segundo Calás e Smircich (1999, p.311), as principais contribuições dessa abordagem para o desenvolvimento da teoria feminista foram:

- mostrar as possibilidades e as visões de mundos alternativos fora do patriarcado;

- oferecer "o aumento da consciência" como uma forma única de pesquisa e prática organizacional, desenvolvendo poder político para todos os participantes; e

- documentar práticas alternativas e organizações alternativas, além de oferecer exemplos específicos de organizações não burocráticas bem-sucedidas.

Embora tenha contribuído de várias formas para o desenvolvimento da teoria feminista, essa abordagem também apresenta várias limitações, entre as quais:

- o fato de que a estratégia separatista é utópica, pois a realidade social não respalda as condições para a constituição de "espaços da mulher":

- a visão de que a política pode representar somente os interesses de mulheres brancas e de classe média; e

- atribuir caráter essencial a "gênero" e "mulher", celebrando o "feminino" diante do "masculino", reificando essas características através da saliência dos estereótipos, obscurecendo muitas diferenças importantes, como por exemplo, a existente entre cultura e história (CALÁS; SMIRCICH, 1999, p.311).

\section{Abordagem psicanalítica}

Originária de teorias psicanalíticas, entre as quais, a freudiana, essa abordagem considera que a natureza humana se desenvolve tanto biológica quanto psicologicamente e que os indivíduos criam sua identidade sexual como parte de seu desenvolvimento psicossexual. Para os adeptos dessa abordagem, gênero seria a estrutura de um sistema social de dominação masculina (ALSOP; FITZSIMONS; LENNON, 2002), e a explicação fundamental para a forma como as mulheres agem e pensam estaria fortemente enraizada na sua psique. A base para a desigualdade entre os gêneros estaria enraizada numa série de experiências na infância. Estas, por sua vez, resultariam não apenas na visão dos homens enquanto sexo masculino e das mulheres enquanto sexo feminino, mas também no ponto de vista das sociedades patriarcais de que o masculino é melhor do que o 
feminino (TONG, 1998, p.131). Na visão psicanalítica, a inferioridade feminina estaria baseada na falta do pênis, conforme explica Tong (1998). Nesse sentido, durante a década de 1970, muitas feministas fizeram de Freud um alvo comum. Para Betty Friedan (apud TONG, 1998), a cultura moldara as idéias de Freud, cujo aforismo de que "anatomia é o destino" significaria que a falta do pênis determinou o papel reprodutor, a identidade de gênero e as preferências sexuais da mulher, a qual poderia ser considerada anormal caso não seguisse o "rumo da natureza" (TONG, 1998, p.135). Nessa perspectiva, se o "pênis" é a base da estrutura de dominação, uma sociedade sem desigualdades seria aquela que não levasse isso em conta, onde, por exemplo, os pais dividissem a responsabilidade pela criação dos filhos (CALAS; SMIRCICH, 1999). Se os pais tivessem um papel tão ativo quanto o exercido pelas mães, as crianças cresceriam reconhecendo que ambos têm fraquezas e forças e que nenhum dos dois é culpado pela condição humana (TONG, 1998).

A posição epistemológica dessa abordagem é a de que o modo de conhecimento das mulheres é diferente do masculino em razão do desenvolvimento psicossexual diferente (CALÁS; SMIRCICH, 1999, p.279). Hirschman e Holbrook (1992) propõem que o significado emana de estruturas mentais pré-existentes. Os adeptos dessa abordagem desafiam as suposições de que a relação pesquisador/respondente possa ser independente e separada (BRISTOR; FISCHER, 1993). As metodologias preferidas pelos adeptos dessa abordagem são os estudos de caso com foco nas relações sociais e nos processos de desenvolvimento, e as histórias de vida (CALÁS; SMIRCICH, 1999, p.279).

\section{Abordagem marxista}

Essa abordagem surgiu baseada na crítica marxista da sociedade capitalista. "Não é a consciência dos homens que determina sua existência, mas sua existência social que determina sua consciência" (MARX, 2003).

De acordo com essa visão, a natureza humana reflete as condições histórico-materiais e a essência humana é o conjunto dos relacionamentos sociais. Como ocorre na abordagem psicanalítica, o gênero é tido como parte das relações de classe que constituem sistemas de opressão, mais do que o sexo (TONG, 1998). Para os adeptos dessa abordagem, é a existência social que determina a consciência. Se pela abordagem psicanalítica a opressão é oriunda do desenvolvimento psicossexual, na abordagem marxista, é constituída pelo regime capitalista. $\mathrm{O}$ comentário de que o trabalho da mulher nunca está completo é, para as feministas marxistas, mais do que um aforismo: é a descrição da natureza do trabalho da mulher (TONG, 1998). Dessa forma, a "boa sociedade" é uma sociedade sem classes que permite o desenvolvimento pleno da natureza humana, onde, uma vez alteradas as relações entre homens e mulheres, seja possível alterar as identidades de gênero e, com isso, eliminar suas desigualdades (ALSAOP; FITZSIMONS; LENNON, 2002).

A posição epistemológica dessa abordagem é a de que o feminismo precisa adotar o ponto de vista de uma classe oprimida sob o capitalismo, representando os interesses da sociedade como um todo (CALÁS; SMIRCICH, 1999). As metodologias mais utilizadas, segundo Calás e Smircich (1999), são a econometria e as análises de dados macrossociais. Segundo Hirschman e Holbrook (1992), o construcionismo socioeconômico, no qual o pesquisador interpreta o texto do seu interesse usando estruturas de dentro da sociedade onde está imerso e da realidade dessa sociedade também é uma possibilidade metodológica, dentro da abordagem marxista.

\section{Abordagem socialista}

Para Tong (1998), a diferença entre a abordagem socialista e a marxista está mais na ênfase do que na substância. Surgida na década de 1970, a abordagem socialista foi uma tentativa de síntese dos movimentos marxista, psicanalítico e radical, em resposta à insatisfação com o pensamento marxista, segundo o qual a opressão feminina seria menos importante do que a opressão do trabalhador (ALSOP; FITZSIMONS; LENNON, 2002). 
Feministas que adotam a abordagem socialista foram influenciadas pelo pensamento de Althusser e de Habermas. Nessa abordagem, Jaggar e Struhl (1978) questionam a suposição marxista de que antes de ser oprimida pelo homem, a mulher é oprimida pelo capital. Essa abordagem vê a natureza humana como fruto das inter-relações dialéticas entre a biologia humana, a sociedade e o trabalho. $O$ gênero advém de relações/interseções envolvendo sexo, raça, ideologia e experiências de opressão sob o patriarcado e o capitalismo (CALÁS e SMIRCICH, 1999; TONG, 1998). A "boa sociedade", para os adeptos dessa abordagem, eliminará todos os sistemas de opressão, sejam estes baseados em sexo, gênero, raça ou classe. Portanto, a liberação feminina não depende apenas da eliminação do capitalismo, mas está condicionada à eliminação do patriarcado para que, então, o capitalismo seja destruído.

A posição epistemológica dessa abordagem é a de que os pontos de vista feministas representam uma condição histórica particular de opressão mais adequada à compreensão da sociedade contemporânea (CALÁS; SMIRCICH, 1999). Para operacionalizar essa abordagem, as metodologias mais indicadas, segundo seus adeptos, são os estudos de caso e as etnografias institucionais (CALÁS; SMIRCICH, 1999).

\section{Abordagem pós-estruturalista/pós-moderna}

Segundo Nicholson (1990), a teoria feminista entre as décadas de 1960 e 1980 refletia apenas o ponto de vista de mulheres brancas, de classe média européias ou norte-americanas. Sua preocupação não era somente com mulheres, cujas vozes estavam silenciadas, mas também com outras minorias. Ainda de acordo com Nicholson (1990), grande parte do problema era consequiência do legado metodológico que as acadêmicas feministas "herdaram". Segundo Fraser e Nicholson (1990), o "pós-modernismo oferece ao feminismo algumas idéias úteis sobre método, particularmente, uma prudência em relação a generalizações que transcendam as barreiras da cultura e da regionalização".

As abordagens pós-estruturalistas vieram, então, para demonstrar a instabilidade da linguagem como forma de representação. Muitas feministas vêem a abordagem pós-moderna como um reflexo do relativismo da pósmodernidade (NICHOLSON, 1990). Para Flax (1990), as noções de "ser", de conhecimento e de verdade podem ser mais apropriadamente respondidas por abordagens pós-modernas. A linguagem não é só mutável ao longo do tempo, mas também pode ter diversos significados em um mesmo tempo.

Uma corrente pós-estruturalista se desenvolveu a partir da aplicação das idéias de Foucault sobre poder e conhecimento e dos pontos de interseção entre corpo, discurso e práticas. Esta visada compreende uma coleção de abordagens ecléticas de diversas fontes, tais como a incredulidade pós-moderna de Lyotard a respeito de metanarrativas, uma certa suspeita em relação à constituição do "feminismo" dentro da modernidade, e as consequências negativas da descontrução dessa imagem por uma "política feminista" (CALÁS; SMIRCICH 1999, NICHOLSON, 1990).

Para as feministas que seguem as linhas de Derrida e Lacan (CALÁS; SMIRCICH 1999; HEKMAN 1992, HUYSSEN 1990; TONG 1998), a problemática da abordagem feminista pós-moderna se concentra no relacionamento da imagem, e "ser mulher", a figura da "mulher" como o "outro" para o sistema de linguagem dominante, no sistema de regras e conceitos de conhecimento da modernidade.

Assim, os feminismos pós-modernos/pós-estruturalistas permitem interseções mais complexas de gênero e outras categorias sociais, que tanto desconstroem posições analíticas tradicionais (por exemplo, mulheres e opressão feminina como categorias unitárias) quanto abrem espaço para diferentes engajamentos políticos que reconhecem relações assimétricas de poder entre aqueles que pretendem ser o "mesmo" (HARTSOCK 1990, NICHOLSON 1990).

Assim, os feminismos pós-modernos/pós-estruturalistas permitem interseções mais complexas de gênero e de outras categorias sociais, que tanto desconstroem posições analíticas tradicionais (por exemplo, mulheres e opressão feminina como categorias unitárias) quanto abrem espaço para diferentes engajamentos políticos que 
reconhecem relações assimétricas de poder entre aqueles que pretendem ser o "mesmo" (HARTSOCK 1990, NICHOLSON 1990).

Segundo Hekman (1992), a dicotomia sujeito/objeto exclui a mulher do "reino" do sujeito, gerando um profundo efeito na mulher como ser do conhecimento. Fundamentado na crença que o conhecimento, assim como produzido em sociedades falocêntricas, é masculino, e se o sujeito é o único que pode gerar conhecimento, a visada da mulher é excluída desse mundo e, portanto, da racionalidade, da verdade. Nas ciências sociais, os homens são, dessa forma, sujeito e objeto, enquanto as mulheres são apenas objeto do conhecimento. Para Alsop, Fitzsimons e Lennon (2002), a relatividade do "não-pertencimento" feminino dá margem a posições alternativas de subjetividade. Dessa forma, a subjetividade do indivíduo não é vista como fixa ou coerente e a ideia de que o conhecimento pode ser validado pela experiência é seriamente questionada (BRISTOR; FISCHER, 1993).

Como o pós-modernismo rejeita o pensamento universalista, para os adeptos da abordagem feminista pósmoderna, a ideia de se formular um conceito universal tanto para a natureza do homem quanto para a da mulher é uma tentativa fútil (HEKMAN 1990). Para Alsop, Fitzsimons e Lennon (2002), "subjetividade" e "consciência" são efeitos discursivos, e as mulheres devem reconstruir sua subjetividade em outros termos que não através de discursos falocêntricos (já que a linguagem é vista como uma criação masculina e por meio dela se dá a dominação feminina). Da mesma forma, para os adeptos dessa abordagem, sexo e gênero são práticas discursivas que constituem subjetividades específicas por meio de poder e resistência na materialidade dos corpos humanos.

O fim da modernidade trouxe uma mudança conceitual e semiótica aos domínios da cultura. Essa mudança não é caracterizada pela crítica moral ou política dos aspectos da modernidade, mas das bases conceituais da modernidade em si mesma (BENHABIB 1990). Denzin e Lincoln (1997) descrevem três crises contemporâneas que discutem a necessidade da condição pós-moderna em relação à pesquisa:

- a crise da representação, em que os modos estabelecidos de representar a realidade são inadequados para a tarefa de pesquisa;

- a crise da legitimidade, na qual os critérios convencionais (validade, confiabilidade e objetividade) para acessar o resultado das pesquisas deixam a desejar; e

- a crise da práxis, em que as contribuições acadêmicas falham na contribuição para resolver, ou mesmo clarificar, os problemas práticos.

Para Benhabib (1990), no final do século XIX, surgiram três direções de críticas à episteme clássica: crítica ao sujeito da episteme moderna, crítica ao objeto da episteme moderna e crítica ao conceito dos símbolos modernos. Portanto, a base da epistemologia pós-moderna se encontra em uma tradição de crítica iniciada por Sausurre e Peirce.

Esta mudança significou que o foco não está mais no sujeito epistêmico, nem no conteúdo privado da sua consciência, mas no público, significando atividades de uma coleção de sujeitos. Não só houve uma mudança do tamanho da unidade de interrogação epistemológica de ideia, sensação e conceito do caráter do signo como significante, significado e interpretante (Peirce), mas também da linguagem e da parole (Saussure) ou dos jogos de linguagem como "formas de vida" (Wittgenstein). A identidade do sujeito epistêmico também muda: o portador do signo não é um ser isolado - não existe linguagem particular, como observado por Wittgenstein $\square$, ou é uma comunidade de "eus" cuja identidade se estende tão longe quanto seu horizonte de interpretações (Gadamer) ou é uma comunidade social de usuários de uma língua existente (Wittgenstein). Esse aumento do conceito de sujeito epistêmico é uma opção. A outra opção, seguida pelos estruturalistas franceses, é negar que, para que um objeto epistemológico tenha sentido, é necessário apelar para um sujeito epistêmico de qualquer forma. $O$ 
sujeito é substituído por um sistema de estruturas e différances que, para ser inteligível, não precisa ser visto como produto de uma subjetividade vivente. (BENHABIB, 1990, p.112)

Concordando com Benhabib, Hirschman e Holbrook (1992) comentam que a base epistemológica do pósmodernismo vem do questionamento da conexão do conhecimento ao empiricismo moderno. "Se o conhecimento não se origina de uma realidade 'lá fora', de onde vem?" (p.2). Em seu livro, Hirschman e Holbrook (1992) sugerem que abordagens pós-modernas tendem a ver o mundo como textos, e as metodologias que podem ser usadas para compreendê-lo são descritas como metáforas em relação a essa condição: o empiricismo é descrito como reflexão do texto; o racionalismo, como criação de texto; o construcionismo socioeconômico, como sistematização do texto; o interpretativismo, como tradução do texto; e o subjetivismo, como construção do texto. Calás e Smircich (1999), por sua vez, e de forma mais menos descritiva e mais sugestiva, propõem o uso de genealogias foucaultianas.

De acordo com Calás e Smircich (1999) e Tong (1998), algumas contribuições para a abordagem pós-moderna são particularmente importantes. Primeiramente, é importante o foco na natureza discursiva da "realidade social" e da "subjetividade", bem como na sua natureza não essencial. A conseqüente ênfase na linguagem como um sistema de diferenças permite questionar os limites impostos ao "conhecimento" por certos discursos privilegiados. Em segundo lugar, a abordagem pós-moderna permite a articulação da "política do conhecimento" como uma forma de relações de poder que tenta naturalizar um sistema de exclusão para certas posições de sujeito (por exemplo, de gênero). Em terceiro lugar, a abordagem oferece uma visão mais pluralista de engajamentos políticos, em que "gênero" se torna apenas um argumento entre outros. Também oferece visões mais complexas da localização social e das estruturas de opressão. Por último, a análise desconstrutivista e genealógica provê uma estratégia importante para demonstrar os limites do discurso orgarnizacional e as estruturas (frequentemente, baseadas em distinções de gênero) desses limites.

Não obstante, podemos encontrar limitações. O foco na linguagem e no discurso tem sido frequentemente criticado como insustentável para a política feminista. A ênfase desconstrutivista questiona a possibilidade de existência de uma base positiva para o conhecimento e um sujeito conhecedor. Segundo, as políticas pluralistas não são sempre consideradas fortes o suficiente para eliminar sistemas de exclusão e de opressão histórica, culturalmente localizados em arranjos patriarcais e capitalistas. Outras críticas da desconstrução e de outras análises pós-estruturalistas incluem as acusações de que são elitistas, inacessíveis e cheias de jargões, o que torna difícil sua utilização pela maior parte dos analistas, a despeito de seu inerente esforço de democratização (MARTIN 1988, MORRIS 1988, NICHOLSON 1990).

\section{Abordagem multicultural (terceiro-mundista ou pós-colonialista)}

A abordagem multicultural conseguiu estender os insights pós-modernos e pós-estruturalistas e suas conseqüências lógicas: se o conhecimento ocidental tem sido constituído diferentemente dos "outros", ao tornálos invisíveis, o que aconteceria se esses "outros" pudessem responder? O que aconteceria caso pudessem demonstrar como são constituídos como "outros"? O que aconteceria caso esses outros pudessem reclamar suas próprias especificidades, fora dos dualismos (como, por exemplo, masculino/feminino) presentes nos discursos ocidentais do conhecimento? (CALÁS; SMIRCICH, 1999, p.305).

Análises multiculturais ([pós]colonialistas) vão, dessa forma, além da desconstrução dos textos ocidentais. Elas mostram que a produção do conhecimento no centro (ocidental) é uma forma de autopromoção, implicando a constituição da legitimação do imperialismo e do colonialismo (CALÁS; SMIRCICH 1999, TONG 1998). Essas análises frequentemente focalizam as complexas subjetividades produzidas pelas interseções de gênero, raça, classe, etnia etc. no contexto de relacionamentos específicos entre Primeiro e Terceiro mundos. Elas teorizam sobre posições e relações de sujeitos heterogêneos, diferentes das imagens raciais e de gênero produzidas pelas categorias ocidentais (como "mulheres", "negras") (CALÁS; SMIRCICH 1999; FONSECA 1999; TONG 1998). 
Segundo Calás e Smircich (1999), as origens da abordagem multicultural surgem de interseções dos feminismos ocidentais e das críticas pós-colonialistas das epistemologias ocidentais. Para Tong (1998), existem duas origens: uma baseada no multiculturalismo de feministas norte-americanas e a outra, num feminismo global. Ambas veem o "eu" como fragmentado e acreditam que a base dessa fragmentação é a cultura.

A concepção da natureza humana também pode ser vista de duas formas. A primeira, sendo analisada como um construto ocidental que surgiu ao tornar o "outro" indivisível ou "quase" humano. A segunda, chamada de "essencialismo estratégico", que, segundo Spivak (apud CALÁS; SMIRCICH, 1999), requer que o intelectual desenvolva estratégias específicas para ler a história do colonizado, pontuando a história das mulheres dentro do contexto.

Para Tong (1998), a concepção de sexo/gênero dessa abordagem considera a constituição de subjetividades complexas que vão além dos conceitos ocidentais de sexo/gênero, enfocando aspectos de gênero nos processos de globalização e cultura. Assim, a concepção de "boa sociedade" é a de uma sociedade em que todos sejam verdadeiramente iguais e onde "diferente" não queira dizer "inferior", mas "único". A opressão feminina em uma parte do mundo, frequentemente, é decorrência do que ocorre em outra, e uma mulher só poderá ser livre quando todas as condições de opressão forem eliminadas no mundo inteiro (TONG, 1998).

Para Morris (1988), não se pode considerar a "mulher", mas sim "mulheres". Para essa autora, "mulher" é o sinal de alerta de um problema que aumenta, "errado desde o início" (Ibidem, p.24). Segundo Calás e Smircich (1999), a posição epistemológica dessa abordagem é a de que o "conhecimento" é um sistema de relações de poder imposto pelo Ocidente ao "resto". A pergunta que se deve fazer é: "O que eu sei ou posso saber sobre mulheres das quais eu me diferencio em termos de raça, cultura, classe e etnia?" (TONG, 1998). Wadi (1999) aponta um elemento fundamental a ser considerado nas pesquisas brasileiras, que é a diversidade cultural advinda das diferenças entre as culturas negra e branca e a formação da sociedade, formação essa determinada na sua maior parte pelos bastardos e filhos ilegítimos. Fonseca destaca a necessidade de nos esforçarmos para "visibilizar as identidades mesmas dos agentes sociais, abrindo-lhes espaço e desasfixiando-os do peso determinístico" (Ibidem, p.209). Para isso, devemos buscar outra ordem de complexidade para a análise social.

As metodologias preferidas pelas feministas nessa abordagem são a análise de conteúdo de discursos, a desconstrução/reconstrução pós-colonialista e os testemunhos escritos, além de outras representações híbridas.

De acordo com Calás e Smircich (1999) e Tong (1998), as principais contribuições desta abordagem para o desenvolvimento da teoria feminista foram:

- a problematização do conceito de "gênero", tal como foi constituído no Ocidente, abrindo a possibilidade de outras configurações de gênero e de relações mais complexas entre homens e mulheres, no contexto das múltiplas opressões provocadas pelo capitalismo;

- segundo, a extensão da crítica ao conhecimento ocidental além da desconstrução, ao articular outras possibilidades de conceitualização e subjetividades, produzindo imagens positivas dos sujeitos terceiro mundistas capazes de agir e de representação. Esta abordagem está fortemente focada em culturas e em histórias específicas, bem como em interseções de gênero/raça/classe/etnia;

- terceiro, a demonstração das possibilidades de ação política e de pluralismo político dentro dos limites micropolíticos da vida (organizacional) cotidiana.

- por último, esta abordagem ilustra abordagens adicionais para organizações fora do âmbito da visão ocidental de "organização".

Essas abordagens são freqüentemente exemplificadas nos novos movimentos sociais e novas manifestações de cultura popular surgindo em diversos países (pós) coloniais. 
Entretanto, devemos levar em consideração as seguintes limitações dessa abordagem: primeiro que, em alguns casos, ela está sujeita às mesmas críticas de elitismo e de inacessibilidade da abordagem pós-estruturalista. Segundo, que a tradicional dicotomia da política de conhecimento ocidental/restante deve ser colocada fora do contexto do feminismo ocidental, que deixa "o outro" sem voz e invisível. Além dessas limitações, essa abordagem parece ser particularmente problemática, mesmo para simpatizantes do feminismo pós-moderno, devido às preocupações sobre a aceitação da existência de "outros conhecimentos" fora dos limites do "conhecimento ocidental(izado)".

O que faz essa abordagem particularmente interessante para ser utilizada nesta proposta de pesquisa é a sua visão do que seja colonização, a qual pode abarcar não apenas nossa condição de dominados pelo Primeiro Mundo (principalmente, pelo mundo anglo-saxão), mas também a postura de dominação diante do sujeito do projeto. Como afirma Tong (1998), a abordagem pós-colonialista é sobre as mulheres unindo-se para discutir suas semelhanças e diferenças, tão honestamente quanto possível, e com isso "remover todas as formas de iniquidades" com vistas à criação de uma ordem social mais justa, ajudando a planejar o desenvolvimento tanto no âmbito nacional quanto local. Isso só pode ocorrer desde que haja uma interação entre as mulheres e autenticidade nos nossos esforços para compreender o "outro".

Para Mary Louise Pratt, em uma entrevista a Costa e Diniz (1999), o feminismo foi historicamente identificado com uma mentalidade burguesa, não preocupado com questões sociais. Podemos observar, pelo que Tong (1998) afirma, que a abordagem multicultural, por ser uma "cria" da abordagem pós-estruturalista/pósmodernista, é sobre a libertação, através do poder, dos colonizados. Estas mulheres colonizadas não são apenas membros dos países do Terceiro Mundo, mas também são dominadas, não apenas por homens de todas as classes, mas também pelas mulheres das classes mais afluentes. Dessa forma, a abordagem multicultural (ou terceiro-mundista ou pós-colonialista) é justificável quando o objetivo da investigação é observar mulheres oprimidas por seja lá qual for o capital em jogo - econômico, cultural, estético, político, etc. Ainda na entrevista a Costa e Diniz (1999), Mary Louise Pratt afirma que que é importante que exista um espaço para debater as relações entre conceitos como gênero, raça e classe, entre outros. Como colocou Fonseca (1999),

é o próprio conhecimento e a forma de produzi-lo que entram em questão, uma vez admitido que o tecido social se faz a partir de inúmeras redes e tramas, ficando ao "conhecedor" a consciência de sua incompletude, bem como a realidade dos limites que poderão operar como desafio à pesquisa [...] Ciência compromissada em conhecer o sentido da experiência humana e que, portanto, desloca a ênfase posta na causa para a ênfase posta no sentido. (Ibidem, p. 210).

\section{Conclusão}

A importância deste estudo pode ser demonstrada na seguinte frase de Olesen (2005): a pesquisa feminista gera novas idéias para a produção de conhecimentos sobre situações que oprimem as mulheres, para ação ou pesquisas futuras. Como colocou Farah (2004), ainda somos carentes na área de administração pública, afirmação que pode ser generalizada a toda a área de administração. Ainda não há um volume suficiente de estudos que possibilite a geração de conhecimento e a formulação de uma teoria feminista brasileira.

Olesen (2005) também adverte para o risco de não olharmos de perto as inter-relações de raça, classe e gênero, o que pode levar a um distanciamento das classes menos favorecidas.

Outro campo de pesquisa que pode se abrir é na área de relações humanas e de organizações, em que estudos conduzidos em outros países mostram as mulheres como trabalhadoras invisíveis na esfera doméstica. Acreditamos que isso diga respeito tanto às donas de casa (quer trabalhem apenas em casa ou tenham jornada dupla), quanto às trabalhadoras domésticas. Outros estudos que podem ser realizados devido à carência maior ainda nessa área seriam sobre teoria gay e lésbica. Olesen (2005) também propõe estudos sobre racismo e raça, defendendo a posição de que faltam autoras negras e de outras etnias. 
A necessidade de descobrirmos também uma metodologia que nos seja própria, que tenha a ver com a nossa realidade, encontra respaldo "lá fora". Denzin e Lincoln (2005) chamam a nossa atenção para o "outro" exótico, considerado "inferior" ou "menos civilizado", só porque vem de uma cultura diferente da "deles".

A pesquisa qualitativa é intrinsecamente multimétodo (DENZIN; LINCOLN, 2005). As propostas metodológicas da abordagem multicultural são: a análise de conteúdo de discursos, a desconstrução/reconstrução pós-colonialista, os testemunhos escritos, as histórias de vida e outras representações híbridas. Bishop (2005) propõe uma nova metodologia baseada na forma como os Maoris se relacionam, levando em consideração questões que para eles são preocupantes em uma abordagem de pesquisa: iniciação, benefícios, representação, legitimidade e responsabilização. Embora possam considerar uma pessoa estranha à comunidade conduzindo a pesquisa, essa pessoa deve passar pelo processo de iniciação previsto quando dos encontros realizados, visto que se trata de uma pesquisa coletivista, produzida pela coletividade, em benefício de cada participante. Nessa proposta, tal pesquisa é um diálogo sobre sua própria condução, suas prioridades, políticas e práticas. Nesse sentido, devemos buscar o nosso próprio caminho. 


\section{Referênclas}

ALSOP, R.; FITZSIMONS, A.; LENNON, K. Theorizing gender. Cambridge, UK: Polity Press, 2002.

BENHABIB, S. Epistemologies of postmodernism: a rejoinder to Jean-François Lyotard. In: NICHOLSON, L. J. (Ed.). Feminism/postmodernism. New York: Routledge, 1990.

BISHOP, R. Freeing ourselves from colonial domination in research: a Kaupapa Maori approach to creating knowledge. In: DENZIN, N. K.; LINCOLN, Y. S. (Ed.). Handbook of Qualitative Research. Thousand Oaks: Sage, 2005. p.109-138.

BRISTOR, J. M.; FISCHER, E. Feminist thought: implications for consumer research. Journal of Consumer Research, v.19, n.31, p.518536, Mar. 1993 .

BURRELL, G.; MORGAN, G. Sociological paradigms and organisational analysis. Londres: Heinemann, 1982.

CALÁS, M. B.; SMIRCICH, L. Do ponto de vista da mulher: abordagens feministas em estudos organizacionais. In: CLEGG, S. R.; HARDY, C. et al (Ed.). Handbook de Estudos Organizacionais. São Paulo: Atlas, 1999.

CASALS, P. H. Paradigmas da administração pública na América Latina. In: ENCONTRO NACIONAL DOS PROGRAMAS DE PÓSGRADUAÇÃO EM ADMINISTRAÇÃO - ENANPAD, 22., 1998, Foz do Iguaçu. Anais... Rio de Janeiro: Anpad, 1998.

CATTERALL, M.; et al. Marketing and feminism: a bibliography and suggestions for further research. Marketing Intelligence and Planning, v.17, n.7, p.369-376, 1997.

CERCHIARO, I. Comparison on perceptions of service quality between a developed country and a less developed country. Dissertação de Mestrado em Marketing (MA) Faculty of Business and Law, Kingston University, Kingston, 1996.

Publicações na área de marketing no ENANPAD - um estudo longitudinal. In. SIMPÓSIO DE GESTÃO E ESTRATÉGIA EM NEGÓCIOS DA UFRuraIRJ, 1., 2003, Seropédica, RJ. Anais... [S.I.: s.n.], 2003.

COSTA, C. D. L.; DINIZ, A. G. Mary Louise Pratt: por uma perspectiva crítica feminista. Estudos Feministas, v.7, n.1-2, p.127-140, 1999.

COSTA, J. A. Gender issues: gender as a cultural construct. Advances in Consumer Research, v.21, n. 1, p.372-373, 1994.

CUDD, A. E.; ANDREASEN, R. O. Feminist theory. Oxford, GB: Blackwell Publishing, 2005. p.432.

DENZIN, N. K., LINCOLN, Y. S. Handbook of Qualitative Research. [S.I.]: Sage, 1997.

Handbook of Qualitative Research. [S.I.]: Sage, 2005.

DOBEL, J. P. Paradigms, traditions, and keeping the faith. Public Administration Review, v.61, n.2, p.166-171, 2001.

DOUGLAS, S.; CRAIG, C. S. Advances in international marketing. International Journal of Research in Marketing, v.9, n.4, p.291319, 1992.

EVANS, R. J. Quality versus cost - lessons for the late 1990s. Managing Services Quality, v.5, n.1, p.10, 1995.

FARAH, M. F. S. Gênero e políticas públicas. Estudos Feministas, v.12, n.1, p.47-71, 2004.

FLAX, J. Postmodernism and gender relations in feminist theory. In: NICHOLSON, L. J. (Ed.). Feminism/posmodernism. New York: Routledge, 1990.

FONSECA, T. M. A Dominação masculina. Formas (in)sustentáveis de ser homem e mulher. Estudos Feministas, v.7, n.1-2, p. 206-213, 1999.

FRASER, N.; NICHOLSON, L. J. Social criticism without philosophy: an encounter between feminism and postmodernism. In: NICHOLSON, L. J. (Ed.). Feminism/posmodernism. New York: Routledge, 1990.

GUERREIRO RAMOS. Redução sociológica. Rio de Janeiro: Ed. UFRJ, 1996. p. 273.

HARTSOCK, N. Foucault on power: a theory for women? In: NICHOLSON, L. J. (Ed.). Feminism/posmodernism. New York: Routledge, 1990.

HEKMAN, S. J. Gender and knowledge. Boston: Northwestern University Press, 1992. 
HEMAIS, B.; VERGARA, S. C. O jeito brasileiro de publicar em estudos organizacionais. Revista Organizações e Sociedade, v.8, n.20, p.45-54, 2001.

HIRSCHMAN, E. C.; HOLBROOK, M. B. Postmodern consumer research. Newbury Park, CA: Sage. 1992.

HUYSSEN, A. Mapping the postmodern. In: NICHOLSON, L. J. (Ed.). Feminism/posmodernism. New York: Routledge, 1990.

IBGE - Instituto Brasileiro de Geografia e Estatística. Censo 2000. 2000. Disponível em http://www.ibge.gov.br/censo/divulgacao.shtm, acesso em 11/03/2007.

JAGGAR, A. M. Feminist philosophy. [S.I.]: Westview Press. 2004. ;STRUHL, P. R. Feminist frameworks. [S.I.]: McGraw-Hill Inc., 1978.

MARTIN, B. Feminism, criticism and Foucault. In: DIAMOND, I.; QUINBY, L. (Ed.). Feminism \& Foucault. Boston: Northeastern University Press, 1988.

MARX, K. Contribuição à crítica da economia política. São Paulo: Martins Fontes. 2003.

MENDES, V. L. P. S. Inovação gerencial na administração pública, cidadania e direitos dos brasileiros. In. ENCONTRO NACIONAL DOS PROGRAMAS DE PÓS-GRADUAÇÃO EM ADMINISTRAÇÃO - ENANPAD, 25., 2001, Campinas. Anais... [S.I.]: Anpad, 2001.

MINH-HA. How native is a "native" anthropologist? American Anthropologist, v.95, p.671-686, 1989.

MINTZBERG, H. Managing government, governing management. Harvard Business Review, p.75-83, May/June 1996.

MORRIS, M. The pirate's fiancée: feminists and philosophers, or maybe tonight it'll happen. In: DIAMOND, I; QUINBY, L. (Ed.). Feminism \& Foucault. Boston: Northeastern University Press, 1988.

NICHOLSON, L. J. Feminism/posmodernism. New York: Routledge, 1990.

OLESEN, V. Early millenial feminist qualitative research. In: DENZIN, N. K.; LINCOLN, Y. S. (Ed.). Handbook of Qualitative Research. Thousand Oaks: Sage, 2005.

POLLITT, C. Managerialism and the public services. Oxford: Blackwell Publishers, 1993.

PRAKASH, G.. After Colonialism. Princeton, Princeton University Press, 1995

ROSENBLOOM, D. H. History lessons for reinventors. Public Administration Review, v.61, n.2, p.161-165, 2001.

SAID, E.. Representing the Colonized: Anthropology's Interloctutors. Critical Inquiry, v. 15, p. 205-225, 1989.

TONG, R. P. Feminist thought. Boulder: Westview Press, 1998.

VIEIRA, F. G. D. Por quem os sinos dobram? Uma análise da publicação científica na área de marketing do Enanpad. In: ENCONTRO NACIONAL DOS PROGRAMAS DE PÓS-GRADUAÇÃO EM ADMINISTRAÇÃO - ENANPAD, 22., 1998, Foz do Iguaçu. Anais... Rio de Janeiro: Anpad, 1998.

Panorama acadêmico-científico e temáticas de estudos de marketing no Brasil. In: ENCONTRO NACIONAL DOS PROGRAMAS DE PÓS-GRADUAÇÃO EM ADMINISTRAÇÃO - ENANPAD, 24., 2000, Florianópolis. Anais... Rio de Janeiro: Anpad, 2000.

WADI, Y. M. Olhar a família a partir das relações de gênero. Estudos Feministas, v.7, n.1-2, p.214-221, 1999.

WOLLSTONECRAFT, M. A vindication of the rights of woman. 1972. Disponivel em: http://www.gutemberg.org. Acesso em: 25/09/2005.

WOOD Jr., T.; CALDAS, M. P.. Adopting imported managerial expertise in developing countries. Academy of Management Executive, p.18-32, May 2002.

ZUCKERMAN, M. E.; CARSKY, M. Feminist theory and marketing thought. Advances in Consumer Research, v.19, p.464-471, 1992. 